\title{
SUR
}

\section{LA QUESTION MYCÉNIENNE}

\author{
PAR \\ M. W. HELBIG
}

EXTRAIT

DES MÉMOIRES DE L'ACADÉMIE DES INSCRIPTIONS ET BELLES-LETTRES

TOME XXXV, 2* PARTIE

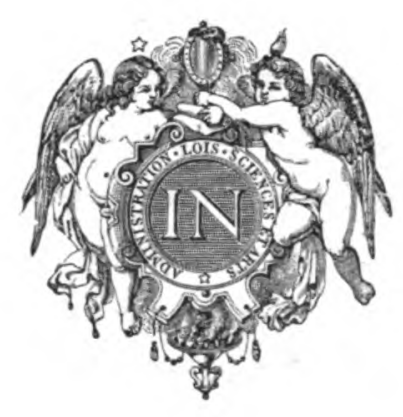

\section{PARIS}

\section{IMPRIMERIE NATIONALE}

\author{
LIBRAIRIE C. KLINCKSIECK, RUE DE LILLE, 11
}

M DCCC XCVI 